\title{
Proton transfer equilibria, temperature and substituent effects on hydrogen bonded complexes between chloranilic acid and anilines
}

\author{
Gamal A. Gohar ${ }^{\mathrm{a}}$ and Moustafa M. Habeeb ${ }^{\mathrm{b}}$ \\ ${ }^{a}$ Chemistry Department, Faculty of Science, Alexandria University, Alexandria, Egypt \\ ${ }^{\mathrm{b}}$ Chemistry Department, Faculty of Education, Alexandria University, Alexandria, Egypt
}

\begin{abstract}
The proton transfer equilibrium constants $\left(K_{\mathrm{PT}}\right)$ for $1: 1$ complex formation between Chloranilic Acid $(\mathrm{CA})$ and a series of $p$ - and $m$-substituted anilines have been measured in 1,4-dioxane spectrophotometrically. The results supported the concept of amine-solvent hydrogen bond formation (short range solvation effect). Beside, this effect, the $K_{\text {PT }}$ values were apparently affected by the electron donation power of the aniline ring substituent, which was transmitted to the interaction center via resonance and inductive effects. Linear relationships between $K_{\mathrm{PT}}$ and $\sigma$-Hammett substituent constants, or $\mathrm{p} K_{\mathrm{a}}$ values for $m$ - and $p$-substituted anilines,were obtained verifying the above conclusions. The solute-solvent hydrogen bond formation might increase the reactivity of the aniline nitrogen than would the inductive effect of the alkyl group, in case of CA- $N$-alkyl aniline complexes. The thermodynamic parameters for the proton transfer complex formation were estimated and it was indicated that the solvent-aniline hydrogen bond formation was preferred in the case of $p$-substituted aniline complexes more than in the case of the corresponding $m$-isomer. It has been found that the proton transfer process was enthalpy and entropy controlled.
\end{abstract}

\section{Introduction}

Quinone chemistry has been already developed in every area including structure, complex formation, synthesis, photochemistry and electrochemistry [1-5]. Quinones have many potential biological applications [6], where they can form proton transfer complexes with enzymes and proteins [7]. They have been used quantitatively for determining the total amino acids in blood plasma and urine [8].

Chloranilic Acid (CA) is one of the important quinones. It behaves either as an oxidant or a reductant. It forms a large number of insoluble salts with a variety of metal cations [9-11]. Because of its diprotic property $\left(\mathrm{p} K_{1}=1.09\right.$ and $\left.\mathrm{p} K_{2}=2.42\right)$, it has been used as an indicator in many titrations [12].

The reported data on the hydrogen bonded complexes of chloranilic acid are limited. Slifkin et al. [13] studied the nature of chloranilic acid complexes and reported that the $1: 1$ complexes were formed in solution, however, the $1: 2$ complexes were formed in the solid state. Agrowi [14] used chloranilic acid as a possible titrant to devise a simple method for determining alkaloids. Moreover, the spectroscopic studies of a large series of 1:1 solid hydrogen bonded complexes between chloranilic acid were presented [15]. Also, the proton transfer equilibria between chloranilic acid and some amines in 1,4-dioxane, were studied spectrophotometrically [16].

In connection with our studies on the hydrogen bonded complexes between chloranilic acid and amines, the present investigation was conducted to compute the intermolecular proton transfer equi- 
librium constants $K_{\mathrm{PT}}$ between chloranilic acid and a series of substituted anilines in 1,4-dioxane at different temperatures by using spectrophotometric methods. This would give more information about the influence of the strength and the structure of the amine, as well as the short range solvation effect on the proton transfer equilibrium constants of chloranilic acid-anilines systems. One major aim of the present investigation is to study the temperature effect and to determine thermodynamic parameters of the proton transfer process in order to know the relation between the amine structure and the strength of the hydrogen bond in the formed complexes as well as the shape of the protonic potential in these complexes.

\section{Experimental}

Chloranilic acid, 1,4-dioxane and the solid anilines are of spectroscopic grade. Liquid anilines were dried over $\mathrm{KOH}$ and double distilled through a $25-\mathrm{cm}$ fractionating column shortly before use and stored in brown bottles. The electronic spectra in the wavelength range of 200 to $800 \mathrm{~nm}$ were recorded on a Shimadzu 160-A UV-VIS recording spectrophotometer, using 1-cm matched silica cell. The temperature was adjusted to an accuracy of $\pm 0.05^{\circ} \mathrm{C}$ by using a TB- 85 thermobath. Different solutions of CA ( $5 \times$ $\left.10^{-3} \mathrm{M}\right)$ and the aniline $\left(10^{-3}\right.$ to $\left.0.3 \mathrm{M}\right)$ in 1,4-dioxane were thermostated at the desired temperature for one hour and the electronic spectra were measured.

\section{Methods of calculation}

The equilibrium constants of $1: 1$ proton transfer complex formation for the investigated systems were calculated at a given wavelength by applying the minimum-maximum method, where the composition of the CA-aniline mixture was calculated directly from the known concentrations of the reactants and the minimum-maximum absorptivities of the CA and the formed complex [16-20].

The thermodynamic parameters were obtained from average $\ln K_{\mathrm{PT}}$ values at various temperatures from 20 to $50^{\circ} \mathrm{C}$ for $1: 1$ proton transfer complex formation between CA and the anilines. Values of $\Delta G^{\circ}$ were based on the values of $\ln K_{\mathrm{PT}}$ at $25^{\circ} \mathrm{C}$ on a line representing the least square fit of $\ln K_{\mathrm{PT}}$ versus $1 / T$. Values of $\Delta H^{\circ}$ were obtained from the slope of this line, and $\Delta S^{\circ}$ values were calculated as $\left(\Delta H^{\circ}-\Delta G^{\circ} / T\right)$

\section{Results and discussion}

Chloranilic acid exists in three forms [14] (Fig. 1); namely the neutral yellow $\mathrm{H}_{2} \mathrm{~A}$ form at a very low $\mathrm{pH}$, the pale violet $\mathrm{A}^{-2}$ form, which is stable at higher $\mathrm{pH}$ and the most stable dark violet $\mathrm{HA}^{-}$form at $\mathrm{pH}=2-4$. In water, acetonitrile and DMF chloranilic acid gives a purple colour which is characterized by an absorption band at $530 \mathrm{~nm}$ in the UV-visible spectrum. As the reaction product in non-aqueous media is purple in colour, it could be concluded that the $\mathrm{HA}^{-}$is the form of chloranilic acid involved in the complexation.

The chloranilic acid solution in 1,4-dioxane was yellow in colour, suggesting the presence of the $\mathrm{H}_{2} \mathrm{~A}$ form. The UV spectrum of chloranilic acid was measured in 1,4-dioxane and it showed two absorption bands at 301 and $420 \mathrm{~nm}$. The absorption band at $301 \mathrm{~nm}$ could be assigned to $\pi-\pi^{*}$ transition within the electronic system of quinonoid ring, while the second band at $420 \mathrm{~nm}$ was presumably due to the proton 
<smiles>O=C1C(O)=C(Cl)C(=O)C(Cl)=C1Cl</smiles>

$\mathrm{H}_{2} \mathrm{~A}$<smiles>O=C1C(=O)C(O)C(=O)C(Cl)=C1Cl</smiles>

$\mathrm{HA}^{-}$<smiles>O=C1C(=O)C(O)C(=O)C(Cl)=C1Cl</smiles>

$\mathrm{A}^{-2}$

Fig. 1. The forms of chloranilic acid.

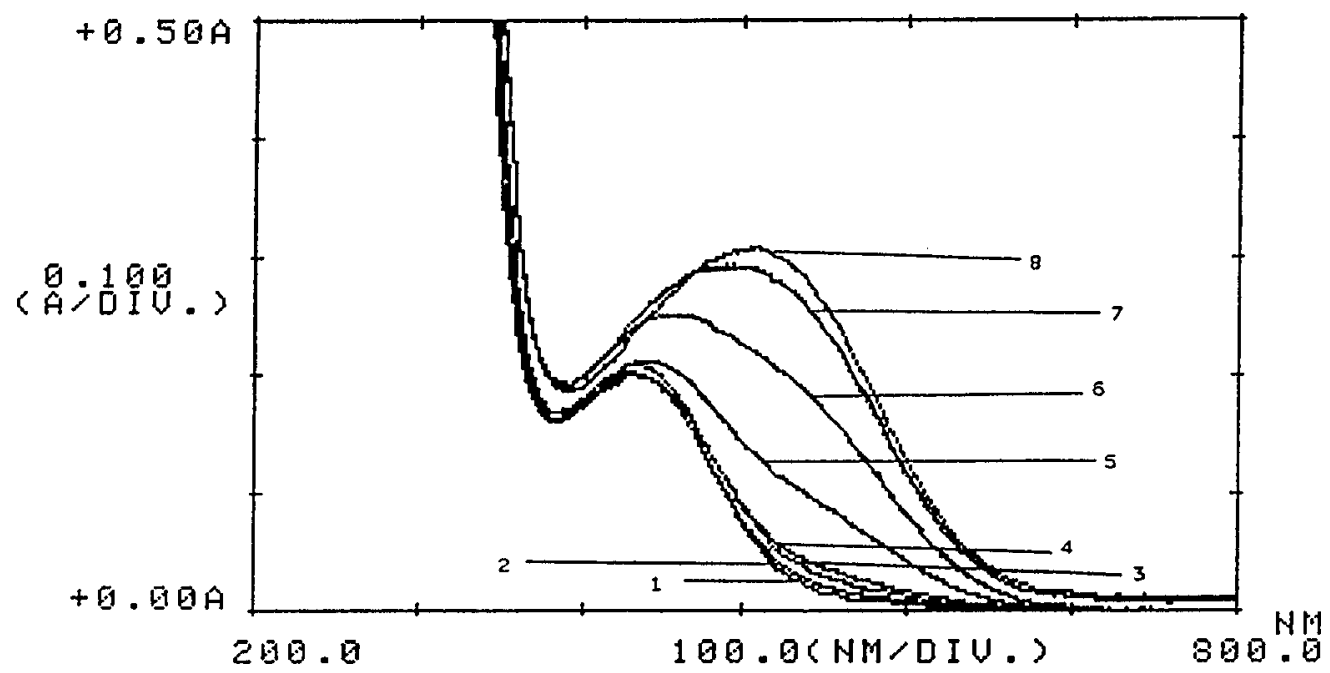

Fig. 2. Absorption spectra of $5 \times 10^{-3} \mathrm{moll}^{-1} \mathrm{CA}$ in the presence of different $m$-toluidine concentrations: (1) 0.0 , (2) $10^{-3}$, (3) $5 \times 10^{-3}$, (4) $8 \times 10^{-3}$, (5) $10^{-2}$, (6) $3 \times 10^{-2}$, (7) $6 \times 10^{-2}$ and (8) $10^{-1} \mathrm{~mol}^{-1}$.

transfer between chloranilic acid and dioxane. It is interesting to note that the second band at $420 \mathrm{~nm}$ of chloranilic acid was shifted bathochromically to $530 \mathrm{~nm}$ in the presence of anilines, which could be ascribed to the existence of $\mathrm{HA}^{-}$form of chloranilic acid [21]. Therefore, the range of 420 to $530 \mathrm{~nm}$ was selected to study the $1: 1$ proton transfer equilibria between chloranilic acid and anilines.

The electronic spectra of chloranilic acid in 1,4-dioxane were recorded in the region from 420 to $530 \mathrm{~nm}$ in the presence of various anilines with different concentrations at $25^{\circ} \mathrm{C}$. Figures 2 and 3 represent the electronic spectra of the hydrogen bonding interaction between chloranilic acid and $m$-toluidine or $N, N$-dimethyl aniline, respectively. By gradual increase of the aniline concentration, a new band appeared at $520 \mathrm{~nm}$ that was corresponding to the proton transfer complex. It was obviously observed from the obtained spectra that there was no any isosbestic point, suggesting the presence of many equilibria including $\mathrm{CA}$ and anilines. Also the $\mathrm{HA}^{-}$form showed a band near $530 \mathrm{~nm}$ and the formed complexes exhibited bands at the region from 500 to $520 \mathrm{~nm}$ conforming the presence of $1: 1$ proton transfer equilibria between $\mathrm{H}_{2} \mathrm{~A}$ and anilines [HAH. . . $($ aniline $) \leftrightharpoons \mathrm{HA}^{-} \ldots \mathrm{H}^{+} \mathrm{N}($ aniline $)$ ]. On the other hand, the $\mathrm{p} K_{\mathrm{a}}$ values of the investigated anilines (3.91-6.56) are not higher enough, therefore, the free ion pair from $\mathrm{HA}^{-}$and $\mathrm{H}^{+} \mathrm{N}$ (aniline) possibly might be not formed. All these facts are rationalized to confirm the presence of $1: 1$ proton transfer equilibria including $C A$ and anilines.

The proton transfer equilibrium constants of the hydrogen-bonded complexes of CA-anilines systems at $25^{\circ} \mathrm{C}$ and their characteristic data are collected in Table 1. 


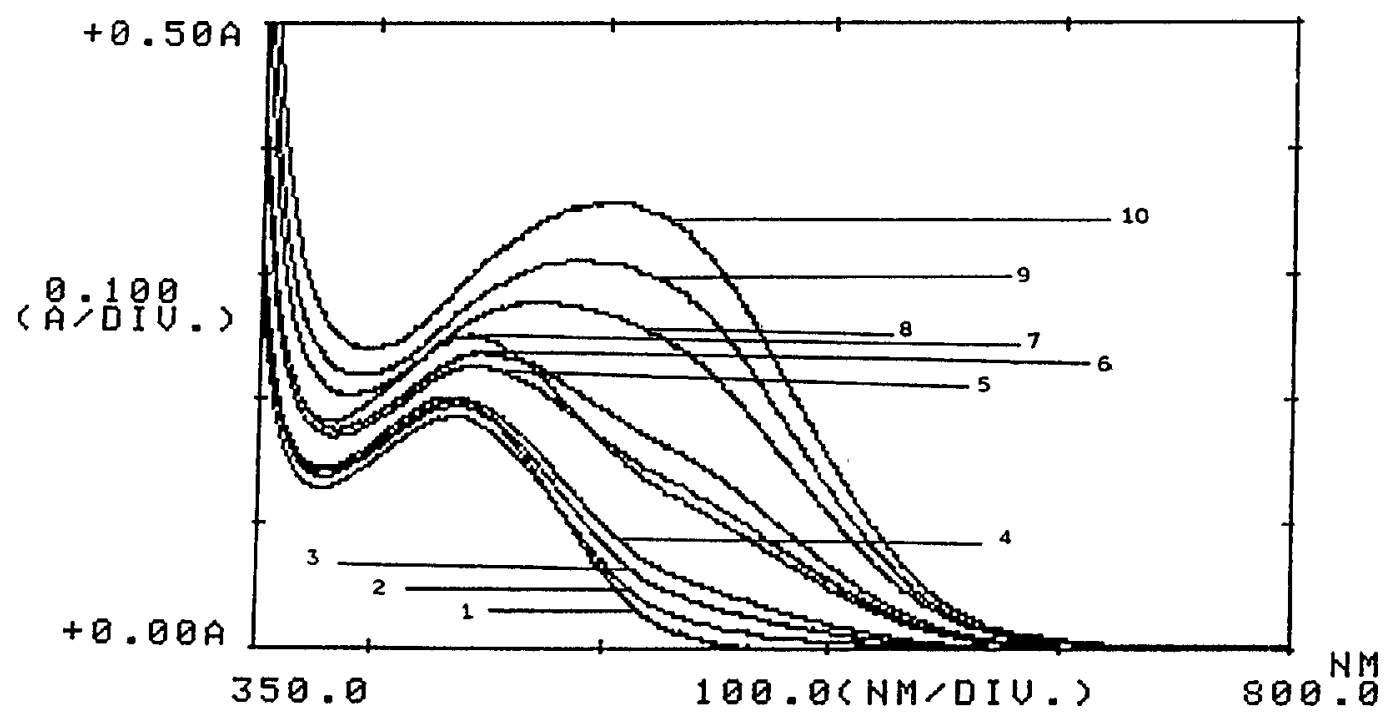

Fig. 3. Absorption spectra of $5 \times 10^{-3} \mathrm{moll}^{-1} \mathrm{CA}$ in the presence of different $N, N$-dimethylaniline concentrations: (1) 0.0 , (2) $10^{-2}$, (3) $2 \times 10^{-2}$, (4) $3 \times 10^{-2}$, (5) $6 \times 10^{-2}$, (6) $8 \times 10^{-2}$, (7) $10^{-1}$, (8) 0.2 , (9) 0.18 and (10) $0.25 \mathrm{moll}^{-1}$.

Table 1

$\mathrm{p} K_{\mathrm{a}}$ of anilines and the intermolecular proton transfer equilibrium constants at $25^{\circ} \mathrm{C}$ for chloranilic acid-anilines systems

\begin{tabular}{lccrcc}
\hline $\begin{array}{l}\text { Aromatic } \\
\text { amine }\end{array}$ & $\mathrm{p} K_{\mathrm{a}}$ & $\begin{array}{c}\sigma \\
(\text { Hammett })\end{array}$ & $\begin{array}{c}K_{\mathrm{PT}} \\
\left(25^{\circ}\right)\end{array}$ & $\begin{array}{c}\text { log } \\
K_{\mathrm{PT}}\end{array}$ & $\begin{array}{c}\text { Conc. range } \\
\left(\mathrm{mol}^{-1}\right)\end{array}$ \\
\hline Aniline & 4.58 & 0.000 & 61.18 & 1.787 & $10^{-3}-8 \times 10^{-2}$ \\
$p$-Bromoaniline & 3.91 & 0.227 & 3.92 & 0.593 & $0.14-0.6$ \\
$p$-Chloroaniline & 3.98 & 0.230 & 28.21 & 1.450 & $0.01-0.2$ \\
$p$-Toluidine & 5.12 & -0.170 & 42.12 & 1.624 & $10^{-3}-10^{-1}$ \\
$p$-Anisidine & 5.29 & -0.270 & 305 & 2.484 & $10^{-3}-4 \times 10^{-2}$ \\
$m$-Bromoaniline & 3.51 & 0.380 & 3.31 & 0.520 & $10^{-3}-0.35$ \\
$m$-Chloroaniline & 3.34 & 0.370 & 3.62 & 0.559 & $5 \times 10^{-3}-1.0$ \\
$m$-Toluidine & 4.69 & -0.070 & 59.12 & 1.772 & $10^{-3}-0.12$ \\
$m$-Anisidine & 4.20 & 0.120 & 25.12 & 1.400 & $10^{-3}-8 \times 10^{-2}$ \\
$N$-methyl aniline & 4.85 & & 18.21 & 1.260 & $10^{-2}-0.20$ \\
$N, N$-dimethyl aniline & 5.06 & & 5.61 & 0.749 & $10^{-2}-0.25$ \\
$N, N$-diethylaniline & 6.56 & & 20.11 & 1.303 & $10^{-3}-0.30$ \\
\hline & & & & &
\end{tabular}

Careful examination of the obtained results in Table 1 showed that the decrease in $K_{\mathrm{PT}}$ values for CA-anilines complexes had the following order: $p-\mathrm{OCH}_{3}>\mathrm{H}>m-\mathrm{CH}_{3}>p-\mathrm{CH}_{3}>p-\mathrm{Cl}>$ $m$ - $\mathrm{OCH}_{3}>N, N$-diethyl $\sim N$-methyl $>N, N$-dimethyl $>p$ - $\mathrm{Br} \sim m$-Cl $\sim m$ - $\mathrm{Br}$ anilines. Also, the $K_{\mathrm{PT}}$ value for $\mathrm{CA}$-aniline complex was the highest one, except for $\mathrm{CA}$-anisidine system. The data pointed out that the intermolecular proton transfer process of CA-anilines was strongly influenced by the anilinedioxane hydrogen bond formation, which increased the basicity of the aniline nitrogen atom; i.e., short range solvation effect [22-24]. On the other hand, this effect was apparently affected by the resonance and inductive effects of the aromatic nucleus substituent of aniline moieties. Therefore, the $K_{\mathrm{PT}}$ value increased as the electron donation power of aniline substituent increased, which could be transmitted to the nitrogen atom via resonance and inductive effects. 
The complex formation between the $\mathrm{NH}_{2}$ group hydrogens of $p$-anisidine and 1,4-dioxane together with the strong electron donation power of $p-\mathrm{OCH}_{3}$ group $(\sigma=-0.27)$, which was in a direct conjugation with $\mathrm{NH}_{2}$ group, were responsible for the highest $K_{\mathrm{PT}}$ value $\left(305 \mathrm{lmol}^{-1}\right)$. This, also, can be ascribed to the existence of the relatively stable planar polar resonance structure (1) of the proton transfer complex, as follows:

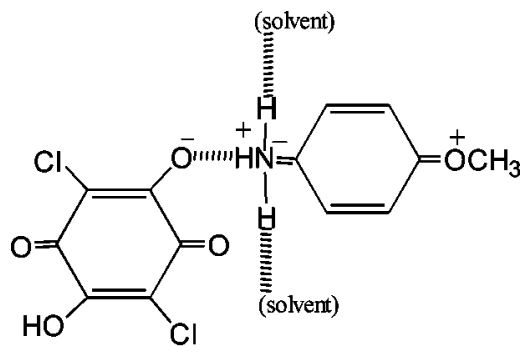

Structure (1)

Furthermore, in case of CA- $p$-toluidine complex, $K_{\mathrm{PT}}$ recorded a smaller value $\left(42.21 \mathrm{~mol}^{-1}\right)$, compared with that in case of $p$-anisidine, although they had nearly equal $\mathrm{p} K_{\mathrm{a}}$ values. It seems that the CA- $p$-toluidine complex was a critical one (possessed 50\% proton transfer), which was characterized by a number of anomalies [25]. Our previous data, concerning chloranilic acid-amine formation complexes, showed that the critical point lied near $\mathrm{p} K_{\mathrm{a}} \cong 6$. This suggests that the aromatic amine-solvent hydrogen bond formation increased the basicity of the nitrogen center, leading to an earlier critical point at $\mathrm{p} K_{\mathrm{a}} \cong 5$, as in case of CA- $p$-toluidine complex.

The plots of $\log K_{\mathrm{PT}}$ values, obtained from the interaction of CA with different $m$ - and $p$-substituted anilines in 1,4-dioxane against Hammett $\sigma$-constants or $\mathrm{p} K_{\mathrm{a}}$ of anilines, gave good linearities and they were in harmony with the obtained data (Figs 4 and 5). This, also, confirms that the short range solvation effect, as well as the electron donation power of the aniline substituents via polar and resonance effects, seemed to go in a parallel manner with the change in the $K_{\mathrm{PT}}$ values of the systems under investigation.

The CA-aniline complex recorded a higher $K_{\mathrm{PT}}$ value $\left(61.18 \mathrm{lmol}^{-1}\right)$ than those for CA-N-alkyl anilines complexes $\left(K_{\mathrm{PT}}=18.21 ; 5.61\right.$ and $20.11 \mathrm{lmol}^{-1}$ for CA complexes with $N$-methyl; $N, N$ dimethyl and $N, N$-diethyl aniline, respectively). This can be rationalized by the complex formation

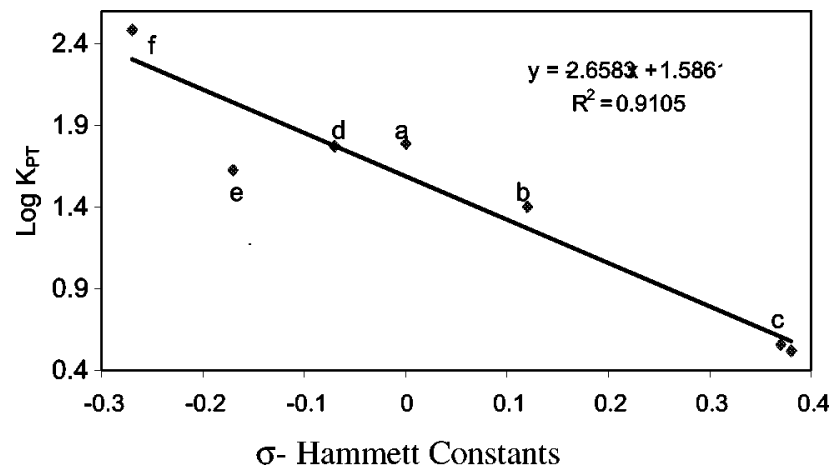

Fig. 4. A plot of $\log K_{\mathrm{PT}}$ of CA-complexes with (a) aniline, (b) $m$-anisidine, (c) $m$-chloro-, bromoaniline, (d) $m$-toluidine, (e) $p$-toluidine and (f) $p$-anisidine against $\sigma$-Hammett constants. 


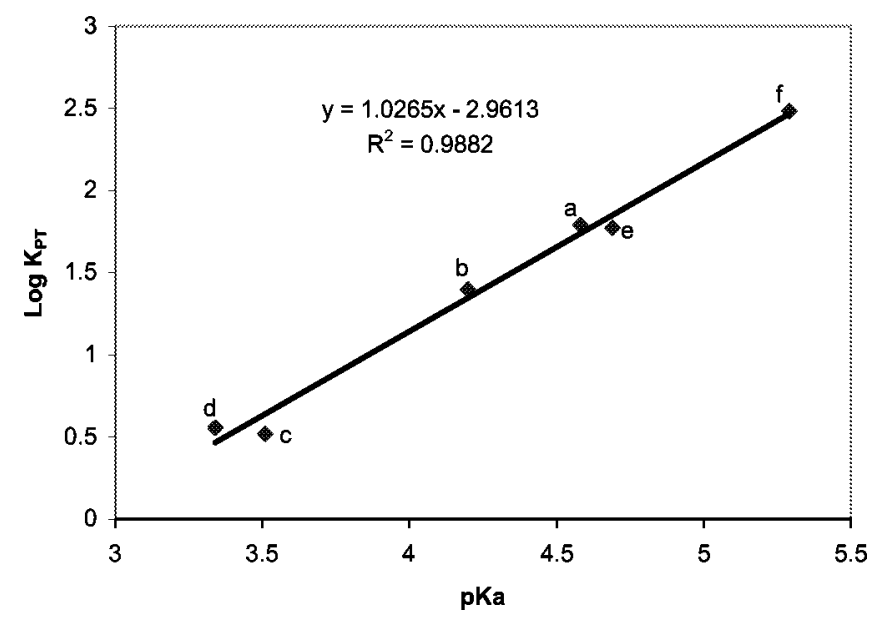

Fig. 5. The correlation between $\log K_{\mathrm{PT}}$ of CA-complexes with (a) aniline, (b) $m$-anisidine, (c) $m$-bromoaniline, (d) $m$-chloroaniline, (e) $m$-toluidine and (f) $p$-anisidine and $\mathrm{p} K_{\mathrm{a}}$ values of anilines.

between the two hydrogens of aniline $\mathrm{NH}_{2}$ group and 1,4-dioxane, which resulted in a relatively higher electron density on the nitrogen atom than that produced due to the inductive effect of the alkyl groups of the $N$-alkyl analogues. Furthermore, CA-N-methyl aniline complex formation showed higher $K_{\mathrm{PT}}$ values than in case of $N, N$-dimethyl aniline, although the latter had higher $\mathrm{p} K_{\mathrm{a}}$ value than the former (4.85 and 5.06, respectively). This behavior can be explained in terms of amine-solvent hydrogen bond formation between the hydrogen of $N$-methyl aniline and 1,4-dioxane. Also, it is observed that the $K_{\mathrm{PT}}$ values, in case of $N$-methyl and $N, N$-diethyl aniline, were nearly equal and this might be attributed to the short range solvation effect, which existed in case of $N$-methyl aniline, that was compensated by the electron donation effect of the two ethyl groups in case of $N, N$-diethyl aniline.

The effect of temperature on the proton transfer equilibrium constants, as well as the thermodynamic parameters of the process, were studied (Table 2). The thermodynamic parameters of the proton transfer complex formation between chloranilic acid and $m$-chloro-, $p$-chloro-, $m$-methyl-, $p$-methyl and $N, N$ dimethyl anilines were estimated and rationalized. The data were collected in Table 3 and depicted graphically in Fig. 6.

It has been found that the proton transfer process of the investigated system was enthalpy and entropy controlled. Both enthalpy and entropy for the $p$-chloroaniline-CA complex formation were nearly twice those estimated for $m$-chloroaniline-CA complex formation, although they had almost the same $\mathrm{p} K_{\mathrm{a}}$ values (Table 1). This observation is presumably attributed to the complex formation between dioxane and the two hydrogen atoms of $\mathrm{NH}_{2}$ group of $p$-chloroaniline, which was comparably hindered in case of $m$-chloroaniline. This led to the strengthening of $\mathrm{OH}^{+} \ldots \mathrm{N}^{-}$bond in case of $p$-chloroaniline-CA complex more than that of $m$-chloroaniline-CA complex by double time. Furthermore, the higher negative value of $\Delta S$ for $p$-chloroaniline-CA reflected a more hindered proton transfer complex where the hydrogen atoms of $\mathrm{NH}_{2}$ group were attached to dioxane molecules. Generally, the values of enthalpies and entropies for these complexes confirm weak hydrogen bonds and on the other hand only one species was present; namely the molecular complex $(\mathrm{OH} . . \mathrm{N})$.

Complexes of $p$ - and $m$-toluidine showed higher enthalpy values $\left(50.6\right.$ and $36.24 \mathrm{~kJ} \mathrm{~mol}^{-1}$, respectively), suggesting strong hydrogen bonds formation involved in these complexes. These results proved the previous conclusion that these complexes belonged to the critical region ( $\cong 50 \%$ proton transfer). Also, it might be observed that the entropy for the $p$-toluidine-CA complex formation was twice that 
Table 2

Effect of temperature on the proton transfer equilibrium constants between CA and some substituted anilines

\begin{tabular}{|c|c|c|c|c|}
\hline Aromatic amine & Temp. $\left({ }^{\circ} \mathrm{C}\right)$ & $K_{\mathrm{PT}}$ & $10^{3} / T$ & $R \ln K_{\mathrm{PT}}$ \\
\hline \multirow[t]{7}{*}{$m$-Chloroaniline } & 20 & 3.60 & 3.40 & 2.56 \\
\hline & 25 & 3.45 & 3.35 & 2.48 \\
\hline & 30 & 3.33 & 3.30 & 2.40 \\
\hline & 35 & 3.18 & 3.25 & 2.31 \\
\hline & 40 & 3.01 & 3.20 & 2.20 \\
\hline & 45 & 2.87 & 3.15 & 2.10 \\
\hline & 50 & 2.81 & 3.10 & 2.00 \\
\hline \multirow[t]{6}{*}{$m$-Toluidine } & 25 & 59 & 3.35 & 8.18 \\
\hline & 30 & 48 & 3.30 & 7.74 \\
\hline & 35 & 38 & 3.25 & 7.27 \\
\hline & 40 & 31 & 3.20 & 6.86 \\
\hline & 45 & 25 & 3.15 & 6.43 \\
\hline & 50 & 20 & 3.10 & 5.99 \\
\hline \multirow[t]{6}{*}{$p$-Chloroaniline } & 25 & 28.21 & 3.35 & 6.68 \\
\hline & 30 & 26.00 & 3.30 & 6.52 \\
\hline & 35 & 23.29 & 3.25 & 6.29 \\
\hline & 40 & 21.50 & 3.20 & 6.13 \\
\hline & 45 & 19.56 & 3.15 & 5.95 \\
\hline & 50 & 17.90 & 3.10 & 5.77 \\
\hline \multirow[t]{6}{*}{$p$-Toluidine } & 25 & 42.0 & 3.35 & 7.47 \\
\hline & 30 & 31.0 & 3.30 & 6.86 \\
\hline & 35 & 22.5 & 3.25 & 6.22 \\
\hline & 40 & 16.5 & 3.20 & 5.60 \\
\hline & 45 & 13.0 & 3.15 & 5.13 \\
\hline & 50 & 9.00 & 3.10 & 4.39 \\
\hline \multirow[t]{6}{*}{$N, N$-diethylaniline } & 25 & 20.0 & 3.35 & 5.99 \\
\hline & 30 & 17.3 & 3.30 & 5.70 \\
\hline & 35 & 16.2 & 3.25 & 5.57 \\
\hline & 40 & 14.1 & 3.20 & 5.29 \\
\hline & 45 & 12.2 & 3.15 & 5.00 \\
\hline & 50 & 11.0 & 3.10 & 4.79 \\
\hline
\end{tabular}

Table 3

Thermodynamic parameters of the formation of hydrogen-bonded complexes of CA with some substituted anilines

\begin{tabular}{lccc}
\hline Aromatic amine & $-\Delta H\left(\mathrm{~kJ} \mathrm{~mol}^{-1}\right)$ & $-\Delta G\left(\mathrm{~kJ} \mathrm{~mol}^{1}\right)$ & $-\Delta S\left(\mathrm{~J} \mathrm{~K}^{-1}\right)$ \\
\hline$m$-Chloroaniline & 6.69 & 2.96 & 12.5 \\
$m$-Toluidine & 36.24 & 18.12 & 60.8 \\
$p$-Chloroaniline & 15.33 & 8.32 & 23.52 \\
$p$-Toluidine & 50.60 & 9.30 & 138.5 \\
$N, N$-Dimethylaniline & 19.50 & 7.46 & 40.0 \\
\hline
\end{tabular}




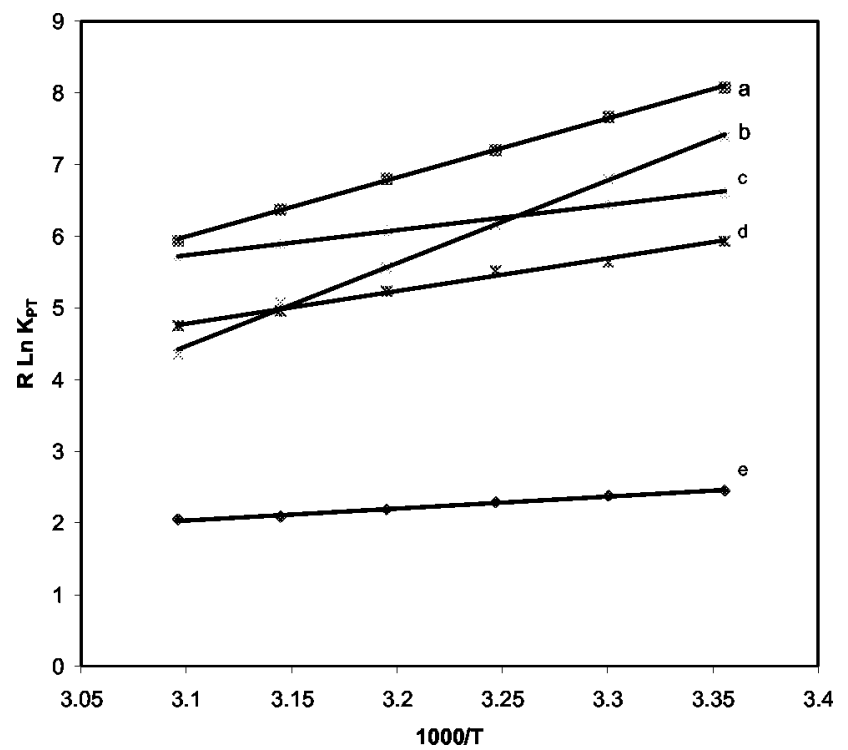

Fig. 6. A plot of $R \ln K_{\mathrm{PT}}$ versus $1000 / T$ for the formation of hydrogen-bonded proton transfer complexes of CA with (a) $m$-toluidine, (b) $p$-toluidine, (c) $p$-chloroaniline, (d) $N, N$-diethylaniline and (e) $m$-chloroaniline.

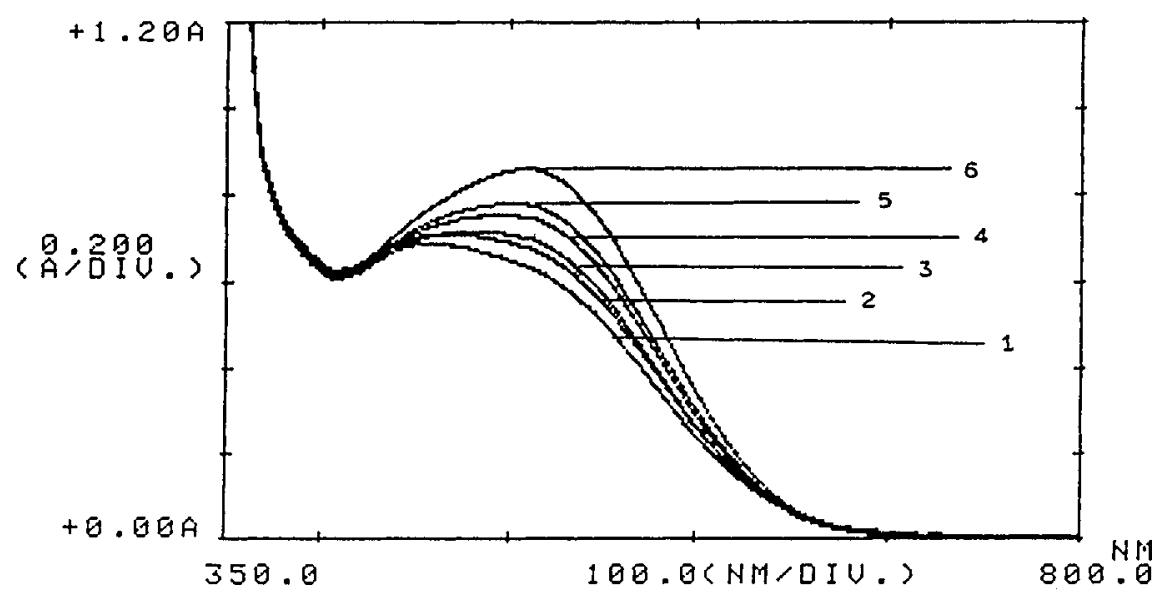

Fig. 7. The effect of temperature at $\lambda=520 \mathrm{~nm}$ for $5 \times 10^{-3} \mathrm{M}$ chloranilic acid and $0.18 \mathrm{M} \mathrm{N}, N$-dimethylaniline in 1,4-dioxane at (1) 60, (2) 53, (3) 46, , (4) 41, (5) 37 and (6) $25^{\circ} \mathrm{C}$.

for the corresponding $m$-isomer, indicating the solute-solvent hydrogen bond formation in case of $p$ substituted aniline complexes, which was preferred due to the coplanarity of the aromatic ring substituent with $\mathrm{NH}_{2}$ group of the aniline in such case and furthermore, more than one species were involved in such equilibrium; namely the molecular complex one $(\mathrm{OH} \ldots \mathrm{N})$, and the proton transfer one $\left(\mathrm{O}^{-} \ldots \mathrm{H}^{+} \mathrm{N}\right)$.

The temperature effect on proton transfer band at $\lambda=520 \mathrm{~nm}$ was analyzed. The results for chloranilic acid and $N, N$-dimethylaniline of $5 \times 10^{-3}$ and $0.18 \mathrm{moll}^{-1}$ concentration, respectively, at the temperature range $25-60^{\circ} \mathrm{C}$, are presented in Fig. 7. As clearly observed in this figure, the increase in temperature shifted the proton transfer band hypsochromically, where it reached $465 \mathrm{~nm}$ at $60^{\circ} \mathrm{C}$, while the decrease in temperature shifted the band bathochromically, where it reached $520 \mathrm{~nm}$ at $25^{\circ} \mathrm{C}$. 


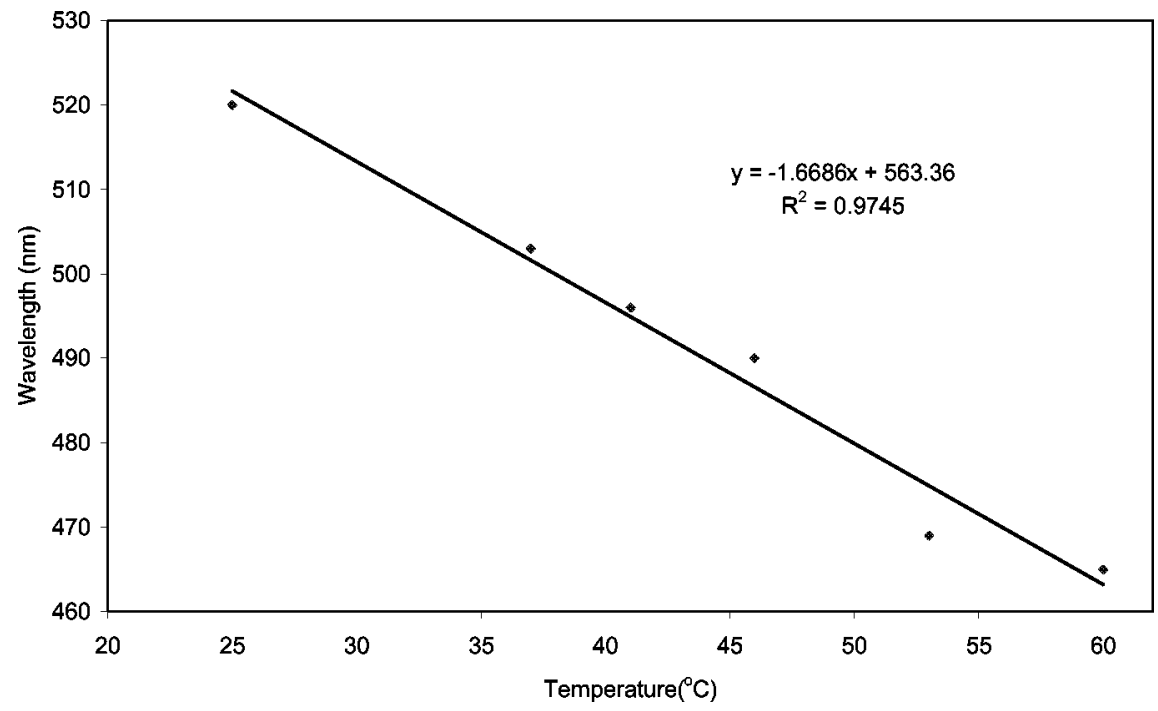

Fig. 8. The correlation of the wavelength $\left(\lambda_{\max }\right)$ for the $\mathrm{CA}-N, N$-dimethylaniline proton transfer complexes with temperature.

A linear correlation was found between $\lambda_{\mathrm{nm}}$ and temperature as shown in Fig. 8. These results can be rationalized in terms of double minimium potential for proton transfer process involved in the complexes under investigation [17].

\section{References}

[1] H. Koshima, Y. Chisaka, Y. Wang, X. Yao, H. Wang, R. Wang, A. Maeda and T. Matsuara, Tetrahydron 50 (1994), 13617.

[2] A. Marchand, S. Bott, V. Godgil, W. Watson, M. Krawice and R. Kashyap, Tetrahydron 49 (1993), 6561.

[3] D. Dubois, G. Moninot, W. Kutner, M. Thomas and K. Kadish, J. Phys. Chem. 96 (1992), 7137.

[4] M. Bauscher and W. Mäntele, J. Phys. Chem. 96 (1992), 11101.

[5] R. Pascal and D. Ho, J. Am. Chem. Soc. 115 (1993), 8507.

[6] R. Driebergen, E. Moret, L. Janssen, J. Blouw, J. Holthuis, J. Kelder, W. Verboom, D. Reinhoudt and W. Linden, Anal. Chim. Acta 257 (1992), 257.

[7] M. Bossa, M. Calapietro, G. Morlurgo, S. Morpurgo and G. Portalone, J. Phys. Chem. 100 (1996), 9302.

[8] D. Zaia, W. Barreto, N. Santos and A. Endo, Anal. Chim. Acta 89 (1993), 277.

[9] M. Rizky, M. Walash and F. Ibrahim, Spect. Lett. 17 (1984), 423.

[10] D. Ward, Inorg. Chem. 35 (1996), 1712.

[11] H. Miyoshi, H. Mihara and S. Kanda, Bull. Chem. Soc. Jpn. 69 (1996), 1933.

[12] K. Cobbiness and E.-S. Amis, Bull. Chem. Soc. Jpn. 40 (1967), 435.

[13] M. Salifkin, B. Smith and R. Wolmsley, Spectrochimica Acta 25A (1969), 1479.

[14] M. El Sayed and S. Agrowi, Talanta 29 (1982), 535.

[15] M. Habeeb, H. Alwakil, A. El-Dissouky and H. Fattah, Polish J. Chem. 69 (1995), 1428.

[16] M. Habeeb, Spect. Lett. 28(4) (1995), 573.

[17] M. Habeeb, E. Hamed, A. Shehata and F. Hegazy, Spectrochimica Acta 51A (1995), 1748.

[18] E. Hamed, M. Habeeb, F. Hegazy and A. Shehata, J. Chem. Eng. Data 40 (1995), 1037.

[19] M. Habeeb and M. El-Kholy, Bull. Soc. Chim. Belg. 106 (1997), 125.

[20] M. Habeeb, G. Gohar, A. Darwish and M. Kharaba, Spect. Lett. 28 (1995), 861.

[21] G. Schwarzenbach and H. Suter, Helv. Chim. Acta 24 (1941), 617.

[22] M. Habeeb, Applied Spectroscopy Reviews 32 (1997), 103.

[23] F. Huyskens, P. Huyskens and A. Persoons, J. Mol. Struct. 448 (1998), 161.

[24] M. Vancamp, S. Morris, A. Mudge, R. Points, J. Knight and R. Scott, J. Mol. Struct. 448 (1998), 143.

[25] S. Melikova, D. Shchepkin and A. Koll, J. Mol. Struct. 448 (1998), 293. 


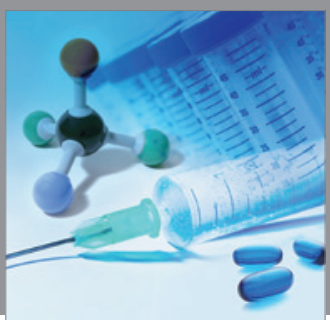

International Journal of

Medicinal Chemistry

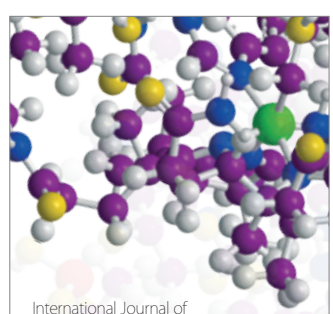

Carbohydrate Chemistry

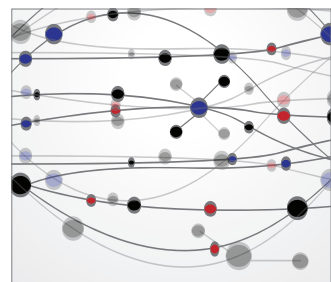

The Scientific World Journal
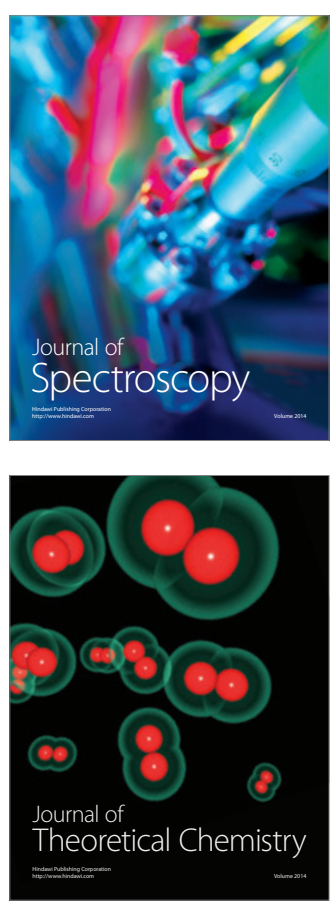
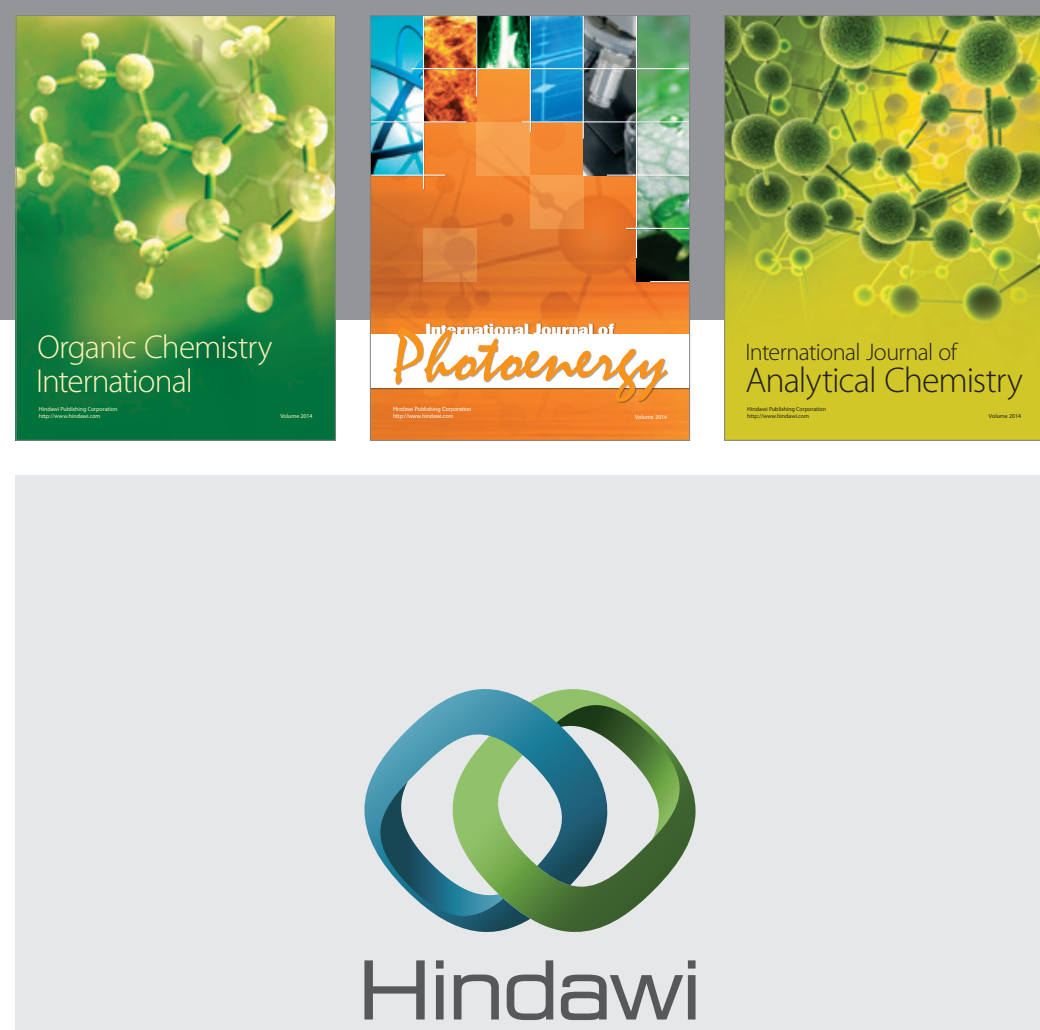

Submit your manuscripts at

http://www.hindawi.com
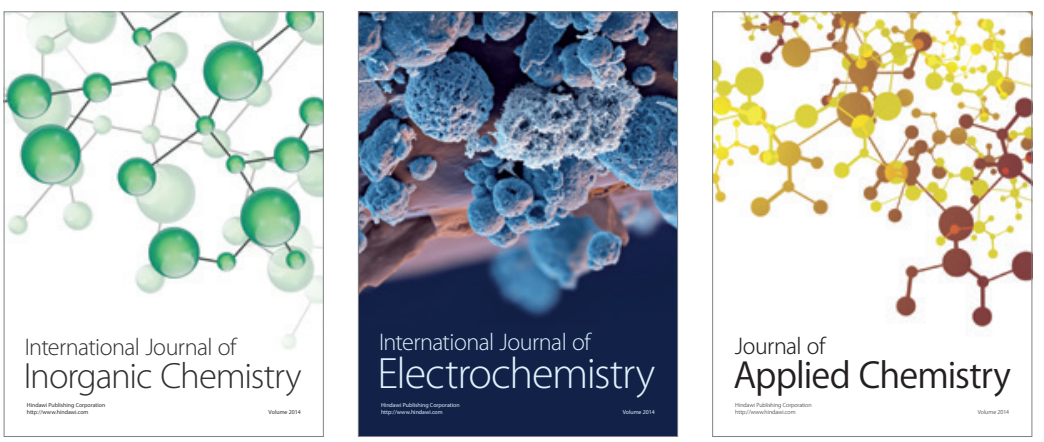

Journal of

Applied Chemistry
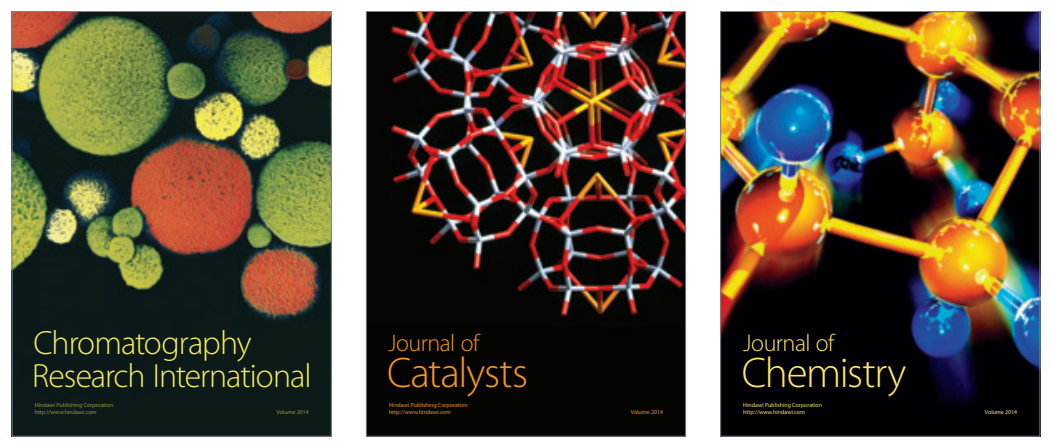
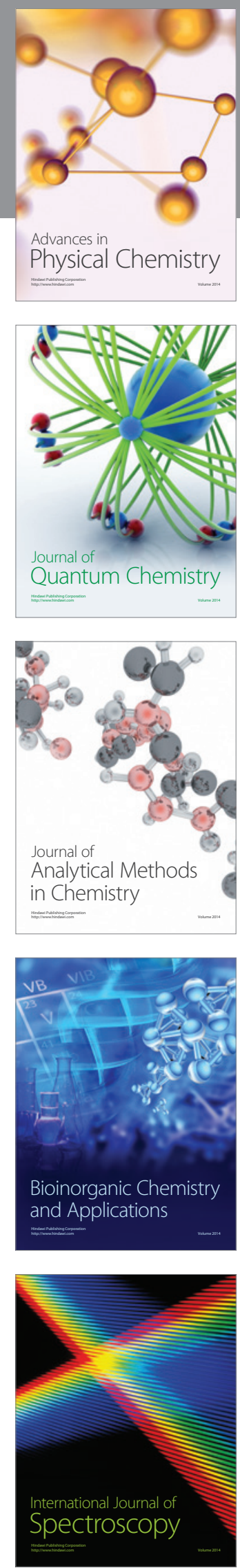